\title{
Analysis of genetic markers and ergovaline production in Neotyphodium endophyte-infected Fescue species collected from Italy, Spain and Denmark
}

\author{
ANNE METTE DAHL JENSEN ${ }^{1}$, LISBETH MIKKELSEN ${ }^{2}$, PRATHAP KUMAR HALADY SHETTY ${ }^{3}$ and NIELS ROULUND ${ }^{4}$ \\ ${ }^{1}$ Center for Forest, Landscape and Planning, The Royal Veterinary and Agricultural University, Rolighedsvej 23 DK 1958 , \\ Frederiksberg C, Denmark \\ ${ }^{2}$ Department of Plant Biology, The Royal Veterinary and Agricultural University, Thorvaldsensvej 40, DK 1871, Frederiksberg C, \\ Denmark \\ ${ }^{3}$ Department of Genetics and Biotechnology, Danish Institute of Agricultural Sciences, Research Center Flakkebjerg Forsøgsvej 1, \\ DK 4200 Slagelse \\ ${ }^{4}$ DLF-Trifolium A/S, Post-box 19, Højerupvej 31, DK 4660, Store Heddinge, Denmark
}

Festuca grasses from various natural habitats are often infected with Neotyphodium endophytes. Genetic variation among the endophytes and variation in their ability to produce ergovaline toxin is also reported. The objective was to determine the endophyte infection frequency, ergovaline production and genetic diversity of Neotyphodium and Epichlóe endophytes in Festuca species sampled from locations in Italy, Spain and Denmark. Endophytes were detected in 57, 54 and 100\% of locations in Italy, Spain and Denmark respectively. Endophyte positive $F$. arundinacea samples from Italian and Danish origin were able to produce a relatively high quantity of ergovaline after 1 month incubation in the climate chamber. However, the isolates from Spain generally produced lower levels of the toxin. None of the F. rubra and F. pratensis produced ergovaline. A dendrogram based on microsatellite length polymorphism separated endophytes of each Festuca species. Further there was a pronounced genetic variation of the $F$. arundinacea endophytes between the countries and within the Italian and Spanish locations. Presently we are investigating the effect of plant genotype on the toxin production. 